\title{
A articulação entre a formação de professores e o ensino-pesquisa socialmente comprometidos
} The relationship between teacher education and teaching-research socially engajed

\section{La relación entre la educación del profesor y la enseñanza-investigación socialmente comprometidos}

\author{
Maria Luisa Bissoto ${ }^{1}$ \\ Antonio Carlos Miranda ${ }^{1}$ \\ Regiane Hilkner ${ }^{1}$
}

DOI: http://dx.doi.org/10.20435/serie-estudos.v22i46.1051

\begin{abstract}
Resumo: Analisa-se uma proposta de formação docente baseada na articulação entre ensino e pesquisa socialmente comprometida, referenciada na Pedagogia Crítico-Democrática, com o objetivo de investigar se os intuitos colocados por essa proposta de formação vem sendo alcançados. São discutidas as possibilidades de tal articulação para formar professores aptos a pensar numa perspectiva emancipatória, entendendo a Educação como bem público. Faz-se um estudo documental dos relatórios de pesquisa dos discentes, desenvolvidas no âmbito do Projeto de Ação Educativa (PAE), nos anos de 2011 a 2013, considerando-se as seguintes categorias: pensar criticamente, problematizar o cotidiano educacional e constituir-se enquanto impulsionador de transformação social. Entende-se que a proposta do PAE, embora suas limitações - dentre estas romper com a consciência ingênuacontribui para a formação do professor questionador da realidade, que reconhece a importância da investigação para a práxis docente e a de se constituir como produtor de saberes.
\end{abstract}

Palavras-chave: formação docente; ensino e pesquisa; Pedagogia crítico-democrática.

\begin{abstract}
We analyze a proposal of teacher education based on the articulation between teaching and socially committed research, referenced in Critical-Democratic Pedagogy, with the objective of investigating if the intentions posed by this educational proposal have been reached. The possibilities to teaching teachers able to think of an emancipatory perspective, understanding Education as a public good following such articulation are discussed. It is a documental study on students' research reports developed under the Educational Action Project (PAE) in the years 2011 to 2013, considering the following categories: to think critically, to problematize the educational daily life and to constitute as a driver of social transformation. It is understood that the proposal of the PAE, although its limitations- among these breakdown the naive conscience-contributes to the formation of a teacher questioning of reality, which recognizes the importance of research for teacher praxis and the one of being a producer of knowledge.
\end{abstract}

Key words: teacher education; teaching and research; critical-democratic Pedagogy.

${ }^{1}$ Centro Universitário Salesiano de São Paulo, Campus Maria Auxiliadora, Americana, São Paulo, Brasil. 
Resumen: Se analiza una propuesta de formación docente basada en la articulación entre enseñanza e investigación socialmente comprometida, referenciada en la Pedagogía Crítico-Democrática, con el objetivo de investigar si los objetivos planteados por esa propuesta de formación se están logrando. Se discuten las posibilidades de tal articulación para formar profesores aptos para pensar en una perspectiva emancipadora, entendiendo la Educación como bien público. Se realiza un estudio documental de los informes de investigación de los discentes, desarrollados en el marco del Proyecto de Acción Educativa (PAE), en los años 2011 a 2013, considerando las siguientes categorías: pensar críticamente, problematizar el cotidiano educativo y constituirse como impulsor de transformación social. Se entiende que la propuesta del PAE, aunque sus limitaciones-desde éstas romper con la conciencia ingenua- contribuye a la formación del profesor cuestionador de la realidad, que reconoce la importancia de la investigación para la praxis docente y de constituirse como productor de saberes.

Palabras clave: formación del professorado; la enseñanza y la investigación; Pedagogía críticodemocrática.

\section{INTRODUÇÃO}

A associação entre ensino e pesquisa tem sido considerada, junto com a extensão, como pilares da Educação Superior, e, no caso do Brasil, referendada em diversos documentos oficiais vinculados ao âmbito acadêmico. Contudo a concretização da interdependência desses campos, ao menos no cotidiano do ensino superior dos cursos de graduação, ainda se encontra em processo de consolidação.

Shin e Cummings (2014), após analisarem especificamente a relação entre ensino e pesquisa nos sistemas de Educação Superior de dezenove países, apontam as múltiplas interpretações, práticas, questionamentos e oposições encontradas ao se pretender conjugar, de forma sistemática, ensino e pesquisa. Concluem que a efetividade de tal conjugação depende de fatores como a qualidade dos recursos disponibilizados para o ensino e a pesquisa, a qualificação do corpo docente, de funcionários de apoio, das convicções pessoais dos docentes sobre pesquisar e ensinar, o tempo que dedicam ao ensino/pesquisa, a flexibilidade da estrutura curricular e das formas de avaliação. Considerando tais fatores, no Brasil, como nos demais países latino-americanos investigados (Argentina e México), o ensino superior se encontra focado principalmente no ensino. Iniciativas de vincular ensino e pesquisa acontecem de maneira pontual, embora venham ganhando espaço na última década. A afirmação de que o sistema de ensino superior brasileiro encontra-se centrado no formalismo do ensino, associado principalmente à reprodução do conhecimento, e menos à produção deste, tem sido corroborada por outros autores, como Severino (2013) e Lampert (2008).

Na definição proposta pelo autor, o binômio ensino-pesquisa pode ser entendido como "uma sequência organizada de situações estimuladoras e desafiadoras 
de aprendizagem, na qual professor e alunos estão envolvidos como sujeitos do processo, na perspectiva de formação de cidadãos críticos, capazes de entender e transformar a realidade circundante" (LAMPERT, 2008, p. 139-40).

$\mathrm{Na}$ análise da historicidade do alinhamento ensino e pesquisa no ensino superior, Malcolm (2013) afirma que este foi decorrente de um movimento de mudança nas concepções educacionais, que passou a ser mais defendido e empregado a partir dos anos de 1990. Num cenário social marcado pela competitividade econômica globalizada, pelo aumento do número de estudantes na escolarização pós-secundária e pelas novas possibilidades de comunicação e de lidar com o saber, abertas pelas tecnologias, houve alterações na dinâmica de produção e distribuição da riqueza, na produção e divulgação do conhecimento, dentre outras. Isso levou a questionamentos sobre qual a missão da universidade nesse novo contexto mundial, tanto do ponto de vista técnico como ético-moral, e sobre como formar o estudante para empregar-se, agir e tomar decisões no âmbito dessas transformações. $\mathrm{O}$ alinhamento ensino e pesquisa, por meio de várias vertentes, que ora acentuam a pesquisa, ora o ensino, vem sendo uma tentativa de responder a tais questionamentos. E tem por base a perspectiva de que a exposição ao processo de pesquisa e o engajamento dos estudantes neste, favoreceria a motivação, o estabelecimento de relações mais estreitas entre teoria e prática e a (re)construção ativa do conhecimento.

Arimoto (2014) assevera que a aceitação da pesquisa na Universidade só começou em fins do século XIX, caracterizando-se pelos princípios humboldtianos de unir pesquisa e ensino. Isso também implicou preocupações ainda contemporaneamente vigentes no ensino superior: a. a liberdade e a autonomia para a pesquisa e o ensino, pois ao caráter de inovação da pesquisa deve equivaler a afirmação do princípio absoluto do conhecimento, e b. a autonomia do estudante, que precisa sair de um papel de passividade para aquele de autoria dos saberes. Nas últimas décadas do século XX, a Universidade, conquanto preservando o modelo proposto por Humboldt em 1810, muda. Quer em termos de público, pois se massifica, quer em termos de seus objetivos- preparar para o mercado profissional, produzir conhecimento, pensar e problematizar a sociedade. Isso requer novos modelos de conceber e praticar o ensino no ambiente universitário, dentre estes, a associação ensino-pesquisa, entendida como forma de enfrentar o rápido anacronismo da formação profissional; aprimorar a qualidade da formação do estudante, preparando-o para a necessidade de aprender ao longo da vida, e fortalecendo a figura do docente como produtor de saberes. Demandas, contudo, difíceis de serem atendidas em 
contextos em que o ensino superior privilegia a formação profissional instrumentalizante, distanciada dos princípios humanistas e da própria intenção de fazer pesquisa, e nos quais a ação do docente fica restrita aos parâmetros formativos demandados pelo mercado.

A concepção do ensino imbricado à pesquisa tem sido justificada, teoricamente, pelo potencial de melhorar-se a efetividade da aprendizagem, ampliando a conjugação entre os saberes teóricos desenvolvidos na comunidade acadêmica e o entorno social, mobilizando a reflexão, a crítica e a própria transformação na produção dos saberes. Em um panorama em que o conhecimento se torna crescentemente mais fluido, como ocorre nas sociedades tecno-industriais urbanas, torna-se relevante que os alunos se apropriem não só de "conteúdos", mas das discussões que envolvem a própria produção do conhecimento. Outras possibilidades didático-metodológicas da vinculação entre ensino e pesquisa se referem à figura do docente: a compreensão do papel do "pesquisador como aprendente, o que permite a melhor compreensão da aprendizagem do estudante; o pesquisador como alguém que tem que lidar com problemas não resolvidos, os quais podem ser transferidos para o ensino" (SANTIAGO et. al., 2014, p. 155); e outros semelhantes. E, ainda, o preparo do aluno para engajar-se na reflexão sobre as evidências e acontecimentos do cotidiano da prática profissional, de maneira crítica e ponderada.

Griffiths (2007) pondera que a vinculação entre ensino e pesquisa pode acontecer de várias formas, dependendo do caráter específico ou difuso da pesquisa, se as atividades de pesquisa estão mais forte ou mais fracamente embebidas naquelas de ensino, e na condução da direção das atividades, ou seja, se é o ensino que informa a pesquisa, ou vice-versa, ou, ainda, se essa condução é bidirecional. Com base nessas considerações, o autor tipifica 04 formas de relacionar ensino e pesquisa, possíveis de coexistirem e mesmo de se sobreporem: a. a pesquisa conduzindo o ensino, sendo o currículo estruturado em achados de investigações; b. o ensino orientado pela pesquisa, em que a ênfase está colocada na compreensão tanto dos processos pelos quais o conhecimento é construído como nos seus resultantes, e os estudantes aprendem processos e métodos de pesquisa; c. o ensino baseado na pesquisa, no qual o currículo é elaborado em torno de atividades de investigação, antes do que na aquisição do conteúdo, e a diferenciação de papeis entre alunos e professores é minimizada e $d$. o ensino informado pela pesquisa, ou a pesquisa pedagógica, em que o ensino está apoiado em investigações sistematizadas do/sobre o processo de ensino e aprendizagem. 
Também contemplando a discussão sobre as formas como o ensino e a pesquisa são/estão imbricados às práticas didáticas, Malcolm (2013) afirma que a ideia mitificada, nas últimas duas décadas, de que a relação ensino e pesquisa seria predominantemente estática, constituindo-se como ensino na/com pesquisa, como a pesquisa direcionando o currículo, ou como ensino para a pesquisa, tem sido recolocada pela concepção de que tal relação é marcada, antes, pela dinamicidade e diversidade de modos de entrosarem-se esses dois termos. Isso também é concernente à variedade mesma dos modos de lidar com a produção e a disseminação de conhecimentos atualmente existente no ensino superior, requerendo que tanto docentes como discentes e outros profissionais da comunidade acadêmica (re) organizem-se continuamente em termos das suas práticas.

Observa-se, contudo, que, apesar das possibilidades de enriquecimento dos processos de ensino-aprendizagem atribuídas ao alinhamento entre o ensino e a pesquisa, há também diversos riscos associados a essa perspectiva. Dentre estes, destaca-se aqui aquele de fragilizar-se a formação e a construção da identidade profissional como decorrência: a. do insuficiente preparo dos docentes- e dos próprios alunos- para envolverem-se em situações de aprendizagem prioritariamente dinâmicas, centradas num papel ativo do aluno em aprender; b. da transformação nas relações de poder requeridas, que exigem novos posicionamentos quanto às responsabilidades que devem ser assumidas no processo de aprendizagem e c. da ausência de um cuidado prévio em desenvolver habilidades e competências pessoais, como aquelas de comunicação, de relacionamento, de agir com autonomia e liderança, dentre outras; fundamentais ao trabalho investigativo. A precariedade dessas habilidades, necessárias a um desempenho satisfatório do estudante ao se alinhar ensino-pesquisa, pode ser prejudicial tanto ao desenvolvimento acadêmico como à formação do futuro pesquisador (BREW, 2006).

\section{COLOCAÇÃO DO PROBLEMA}

O objetivo do artigo em tela é examinar como a vinculação entre ensino e pesquisa pode ser efetivada na graduação em Pedagogia, apresentando-se um estudo pautado na experiência do "Projeto de Ação Educativa", desenvolvido em uma instituição universitária privada sem fins lucrativos, confessional, localizada na macrorregião de Campinas, São Paulo. A hipótese do projeto aqui tratado é a de que a formação do professor deve constituir-se no exercício de pensar criticamente os modos como a realidade vem sendo construída, defendendo uma compreen- 
são da práxis educativa como bem público. Na definição de Nixon (2012), o bem público é entendido não como a somatória de interesses individuais, mas como a apropriação da ideia de que a justiça social e a equanimidade é que devem ser os parâmetros a guiar nossas reflexões e participação na sociedade. Para tanto é essencial a concepção de que ensinar é mais do que "transmitir" ao aluno um "pacote" de conteúdos: envolve modos de interpretar o mundo. Fundamental para o entendimento dessa argumentação é o resgate etimológico do termo interpretar: discutir a valoração feita quanto àquilo que está em jogo, numa dada situação ou conjuntura (SKEAT, 2005).

Tais pressupostos requerem a compreensão da pesquisa não se partindo de uma posição epistemológica $\mathrm{S} \rightarrow 0$, que busca desvelar "verdades" eà qual se encontra coligada uma concepção instrumental do conhecimento: ou como coisa produzida enquanto resultado da investigação ou meio para atingir-se um fim. Contrariamente, entendemos a pesquisa como um processo de imbricamento $S \leftrightarrow O$, no qual as valorações e crenças pessoais do pesquisador, enquanto sócio-historicamente construídas, são indissociáveis da posição assumida por este no curso da ação investigativa. A pesquisa constitui-se numa tomada de consciência das demandas e perplexidades que envolvem o ser e estar-no-mundo. E o conhecimento, um processo de construção de sentidos em relação ao real, a partir do qual se faz possível trazer à reflexão as diversas contradições com a qual convivemos cotidianamente, suscitando outras e novas formas de problematizá-las.

\section{FUNDAMENTAÇÃO TEÓRICA: ENSINO E PESQUISA NA FORMAÇÃO DO PEDAGOGO}

A articulação entre ensino e pesquisa na licenciatura em Pedagogia têm sido defendida por autores como Freiberg e Berbel (2010) e Cunha (2006), dentre outros. A principal argumentação a favor dessa articulação é a de que a formação do pedagogo, quando aliada à pesquisa, se faz relevante para a qualidade dessa formação, pois favorece a capacidade para a indagação problematizadora dos contextos educativos, o despertar da curiosidade quanto às possibilidades da ação educacional e a reflexão crítica sobre a complexidade da prática docente, o que é fulcral para formar-se um profissional não alienado das contradições que vigoram no contexto social. O engajamento em situações de pesquisa também favorece a apropriação dos conhecimentos técnicos próprios à docência, aprimorando a deliberação e as tomadas de decisão pertinentes ao exercício da profissão. 
Um importante obstáculo para que o alinhamento ensino e pesquisa se concretize na formação docente está na concepção dos estudantes de Pedagogia -e também naquela de muitos professores-de que a sala de aula, a estrutura e as práticas escolares, os alunos, o currículo e o material didático são espaços, sujeitos e instrumentos ideologicamente neutros. Traduz-se na ideia de que o conhecimento escolar e a prática docente são igualmente imparciais em si mesmos, direcionando-se para a "melhoria" dos indivíduos e da sociedade (KINCHELOE, 2008). Essa posição de ingenuidade epistêmica tem conduzido a uma prática escolar que se efetiva como a imposição e domínio de uma cultura - aquela dominante, "a partir da qual se legitima o exercício da exploração econômica, da dominação política e da exclusão social" (CHAUÍ, 2008, p. 59)- sobre outras.

Mostra-se, assim, de essencial importância, se pretendemos construir uma educação pautada pelo princípio do bem público, agir para que a formação de professores se configure primordialmente como um processo de desvelamento ideológico e de exercício de interpretação de mundo, promovendo a autonomia do pensar. Os discentes devem conseguir reunir, ao longo da sua formação, condições de reflexão crítica para perceber a Educação como um campo de conflitos e de regulação social, permeado por questões de poder, que se desdobram naquelas envolvendo raça, gênero, classe social, valores ético-morais, e quanto ao ideal de ser humano que se pretende formar, num dado momento histórico, e como tais questões se manifestam nas teorias e práticas educativas.

Obviamente a formação do professor, nessa perspectiva, não pode constituir-se como doutrinária, mas emergir na esteira de um pensar a ação pedagógica como aquela direcionada a constantemente indagar: educar para quê? Que sociedade pretendemos ajudar a construir, com a ação educativa?

Com base nessas convicções quanto às concepções que devem guiar a formação do pedagogo, é que o projeto de formação docente aqui analisado foi formulado. Dirige-se, em seus objetivos, a preparar o futuro professor para conceber a sua ação como práxis: reflexão-ação criadora, preocupada com a qualidade e o respeito à vida humana, efetivada por sujeitos autônomos, conscientes da responsabilidade de que, ao agirem, conformam realidades. Ou, no entender de Freire (1979), como o movimento sinérgico de reflexão e ação, no qual e a partir do qual as pessoas se envolvem em seu processo de emancipação (ou de construir sua libertação), em relação às formas de opressão e dominação às quais estão sujeitas. São essenciais para essa perspectiva a aprendizagem de problematizar a prática, de dialogar dia- 
leticamente e de agir democraticamente, categorias que serão explicitadas abaixo, na análise dos dados.

O enquadramento conceitual que sustenta teoricamente o projeto aqui tratado é aquele da Pedagogia Crítico-Democrática, segundo o qual os sujeitos envolvidos numa situação de aprendizagem se apropriam do conhecimento existente em sua experiência imediata, ampliando sua compreensão de si e dos seus contextos de existência, pelo exercício do pensamento crítico: a tomada de consciência das contradições presentes no entorno. A Pedagogia Crítico-Democrática pode ser definida como o processo de prover os sujeitos com conhecimento, paixão, capacidades cívicas, e responsabilidade social necessárias para endereçar os problemas enfrentados pela nação e pelo globo. Alertando-os de que tal enfrentamento significa

[...] desafiar os modelos de escolarização e de pedagogia amplamente desenhados para promover ganhos econômicos, para criar sujeitos para o consumo, e para substituir o pensamento e a análise críticas pelo treinamento. Tais tendências antidemocráticas e anti-intelectuais têm se intensificado paralelamente à emergência contemporânea de diversos fundamentalismos, especialmente a racionalidade neoliberal focada no mercado, a qual exibe um profundo desdém, se não um total desprezo, tanto pela democracia como pelo ensino e a escolarização publicamente engajados. (GIROUX, 2011, p. 24).

A formação de professores nessa perspectiva não é nova, remontando à década de 1960. Acreditamos que a sua retomada na licenciatura em Pedagogia, associada à ideia de se trabalhar o ensino como investigação socialmente comprometida, se apresenta como uma possibilidade de revisitar questões centrais à formação docente. Abaixo detalha-se como o projeto em pauta se organiza metodologicamente, bem como se analisa uma síntese dos dados levantados a partir dos relatórios de pesquisa elaborados pelos discentes, resultantes das investigações propostas.

O Projeto de Ação Educativa (PAE) é de natureza interdisciplinar, pretendendo efetivar-se, desde 2009, como um processo de ensino-aprendizagem no qual o discente possa articular as habilidades e os conhecimentos teórico-metodológicos das disciplinas curriculares, às competências para problematizar e investigar, com critérios acadêmicos, rigor científico e compromisso social, um determinado tema da realidade educacional, com vistas a planejar e executar ações de cunho pedagógico, que possam intervir nesta. Acompanha, nesse sentido, a preocupação manifestada em documentos oficiais com a integração entre ensino-pesquisa e a atenção a problemáticas históricas na sociedade brasileira. A resolução CNE/CP 1/2006 do Conselho Nacional de Educação, exemplo de um desses documentos, institui as Diretrizes 
Curriculares Nacionais para o Curso de Graduação em Pedagogia, licenciatura, instando a identificar problemas socioculturais e educacionais "com postura investigativa, integrativa e propositiva em face de realidades complexas, com vistas a contribuir para superação de exclusões sociais, étnico-raciais, econômicas, culturais, religiosas, políticas e outras" (BRASIL, 2006).

Operacionalmente, o PAE mostra-se organizado como descrito a seguir. Iniciase no 2 ㅇ semestre de cada ano letivo, estendendo-se até o 6 ㅇ semestre, sendo os sujeitos licenciandos do curso de Pegagogia ${ }^{2}$. Os alunos se reúnem em grupos, com cerca de cinco integrantes cada, sendo todos do mesmo período letivo, e a tendência é a de que esse agrupamento inicial seja mantido ao longo dos semestres. Os grupos contam com a orientação de um docente (professor doutor), o qual, preferencialmente, também permanece com a condução do projeto durante toda a sua realização. Está garantida, na matriz curricular, uma carga horária de 20 horas por semestre para a realização do Projeto.

O trabalho desenvolvido contempla as seguintes etapas, de acordo com o semestre cursado, sequencialmente: a) escolha de um campo- e de um tema- de investigação, relacionado à educação; b) a identificação, a problematização e o estudo de uma realidade educacional em que o tema pesquisado se faz presente, assumindo um posicionamento crítico-reflexivo; c) o planejamento de ações educacionais, que objetivem levantar as contradições existentes nessa realidade, com vistas à intervenção; d) implantação das ações (socio)educacionais planejadas; e) o encerramento do projeto junto à comunidade/grupos envolvidos, com a avaliação das ações e o retorno, aos envolvidos e à comunidade, dos achados resultantes, por meio da produção de artigos e apresentação em eventos acadêmicos. Cada etapa é avaliada ao final do semestre letivo correspondente, por meio de relatórios, diários de campo e relatos de acompanhamento. Todas as etapas são inerentemente marcadas pela intermediação teoria-prática, sem a qual a práxis educativa não se faz possível. Os procedimentos éticos são assegurados por meio da leitura e discussão do "Termo de Consentimento Informado", que é assinado pelos discentes, pelo professor orientador e pelos sujeitos do contexto pesquisado.

\footnotetext{
${ }^{2}$ A partir do ano de 2016, com a mudança curricular de seis para oito semestres, o PAE passou a iniciar-se no 3의 semestre letivo, estendendo-se até o 8o semestre.
} 


\section{METODOLOGIA E ANÁLISE DOS DADOS}

Com a finalidade de avaliar se o Projeto de Ação Educativa vem atingindo o seu objetivo central, que é aquele de formar o discente para a práxis educacional, foram pesquisados dados dos anos de 2011 a 2013, considerando que é a partir desse período que o referido projeto vem alcançando contornos mais definidos. Trata-se de uma análise documental, na qual foram estudados os relatórios de pesquisa entregues pelos discentes nos anos de 2011, 2012 e 2013, totalizando trinta e cinco trabalhos. Tais relatórios foram redigidos pelos alunos ao término das investigações realizadas, e apresentados em eventos acadêmicos institucionais, sendo avaliados por uma banca examinadora. Bryman (2008), referindo-se à pesquisa documental, afirma que a produção textual pode ser de relevância para a compreensão da cultura e do ethos subjacentes às experiências vivenciadas pelos sujeitos. Os textos são reconhecidos não como "espelhamentos" da realidade, mas como documentos redigidos com determinados propósitos, que podem ser mais bem interpretados quando acompanhados de outras fontes de dados, como a observação participante, entrevistas, registros fotográficos ou videográficos, dentre outros. Na análise aqui proposta, o estudo dos relatórios de pesquisa foi guiado também pelas sessões de orientação das pesquisas, e pelo acompanhamento destas pelos professores orientadores.

A partir, então, desses relatórios, das sessões de orientação das pesquisas e do estudo do referencial teórico, emergiram três categorias de análise: a. a aprendizagem de problematizar a prática, b. as competências de dialogar dialeticamente e c. de agir democraticamente. Para fins de identificação, assegurando-se o anonimato, foram atribuídos aos grupos de discentes, de cada ano, uma numeração aleatória, seguida do ano em que o Projeto foi finalizado.

Em relação à primeira categoria, a aprendizagem de problematizar a prática, o elemento central de análise foi a escolha dos contextos nos quais a pesquisa seria realizada, e quais os pontos que seriam tensionados como problemáticas das investigações. Desde que essas escolhas resultam da discussão do grupo entre si, com o aconselhamento indicativo, mas não diretivo do professor orientador, consideramos que se mostram relevantes para compreender como foi sendo construída - ou não - a sensibilização dos alunos para questionar as práticas educativas presentes no entorno, especialmente no sentido de observar se estas se dirigiam a contemplar perspectivas de justiça social e de equanimidade. Pode-se afirmar que 50\% dos 
trinta e cinco trabalhos analisados evidenciaram preocupações com tais perspectivas, envolvendo temas como a Educação em assentamentos do Movimento dos Trabalhadores Sem-Terra (MST), na enfermarias pediátricas de hospitais públicos, educação de jovens e adultos, educação inclusiva, educação em abrigos/casas de acolhimento, educação étnico-racial e em ambientes de vulnerabilidade social. Numa exemplificação das temáticas abordadas e sua problematização, conforme expostas em alguns dos relatórios de pesquisa:

A ação educativa relatada teve duração de três anos e refere-se à experiência de educação em espaço não escolar, realizada em uma instituição assistencial de Santa Barbara d'Oeste. Depois de detectada a problemática do local, sendo esta a falta de atividades dirigidas que compreendessem as crianças de quatro a seis anos, o objetivo foi propor ações para a construção da aprendizagem, não só técnico-formal, mas também, moral e social por meio de atividades lúdicas que realçassem características voltadas também a valores éticos. (Grupo 1, 2011).

Esse projeto de pesquisa pauta-se pela história silenciada de homens e mulheres impedidos de tomarem conhecimentos da sua história, cultura e tradição milenar e ancestral africana, impossibilitando, sobretudo, que crianças afrodescendentes obtivessem um reconhecimento genuíno, dos feitos ancestrais. Com base em nossa pesquisa identificamos que a Lei 10.639/03 possui uma "brecha", em que não exige a obrigatoriedade da formação de professores... (Grupo 1, 2012)

O objetivo deste trabalho foi verificar se a inserção da criança autista na escola pública, sob a égide da lei, vem garantindo o seu desenvolvimento e interação social, cotejando estas inserções. Ao longo do percurso, nossa investigação se ateve a analisar se os discursos inclusivos têm sido coerentes com a prática. (Grupo 7, 2012).

O que pretendemos com nossa pesquisa foi refletir sobre a questão educação e saúde pública, principalmente em como a população recebe as orientações do posto de saúde, pois são orientações que, muitas vezes, não são entendidas claramente pelo indivíduo, são informações frequentemente superficiais, mal explicadas, ou com termos técnicos, que não são compreendidas como deveriam. Isto pode estar relacionado também ao papel do pedagogo, acreditando que este pode ser um profissional que colaborará para a melhora das condições da educação em saúde, favorecendo uma melhor qualidade tanto na adoção e discussão de práticas saudáveis como na organização da população para lutar por melhores condições de saúde. (Grupo 4, 2013).

Contudo, se, por um lado, a porcentagem de investigações que procuraram problematizar criticamente as práticas educativas dos cenários investigados se 
mostre promissora numa formação que pretende preparar o profissional para enfocar a educação como bem público, por outro lado, os enfoques teóricos dados às problematizações mostraram fragmentação e ecletismo. Dez por cento (10\%) basearam-se na Psicologia Histórico-Cultural, 12\% em Paulo Freire, e outros 15\%, em referenciais que apontam para algum tipo de teoria voltada para o desenvolvimento do pensamento crítico. Os demais trabalhos (67\% do total) empregaram referenciais diversificados, não claramente identificados ou que mostraram uma apropriação superficial daqueles; o que pode representar dificuldades para o aprofundamento e tratamento das problematizações propostas.

Argumentamos que essa dificuldade na devida apropriação das bases teóricas pertinentes ao campo da Pedagogia, ou das suas áreas afins, pode ser representativa da dicotomia entre teoria e prática, na formação de professores. Estudos de Mandú e Aguiar (2013) apontam que, principalmente a partir do final da década de 1960, com a influência do tecnicismo nos cursos de Pedagogia, ocorre uma fragmentação na formação do professor. Teoria e prática se desarticulam, valorizando-se a "prática" instrucional, em detrimento da densidade da apropriação teórica. Embora a perspectiva tecnicista seja combatida ao menos desde 2006, especialmente com as Diretrizes Curriculares Nacionais, outras tendências teórico-metodológicas, vinculadas a matrizes diversas, parecem perpetuar, nos cursos de formação de pedagogos, o privilégio do conhecimento tácito (relacionado ao contexto das vivências cotidianas, de cunho prioritariamente pessoal e circunstancial), colocando, em segundo plano, o conhecimento científico-acadêmico (MARTINS; DUARTE, 2010). Entretanto, se no processo de elaboração da pesquisa essa dicotomia se tornou aparente com mais nitidez, pois tratava-se de teorizar a prática, também revelou-se aí, para os alunos, a necessidade imanente da teoria para melhor compreender as muitas dimensões da Pedagogia e da Educação. Ainda que tal necessidade não tenha se traduzido, em muitos dos trabalhos, num melhor tratamento imediato dos referenciais teóricos, houve a conscientização do aluno quanto à importância do conhecimento científico para a qualidade do exercício da profissão docente.

A competência de dialogar dialeticamente foi analisada pelos seguintes pontos: comunicar-se com os demais, de modo aberto e receptivo às diferentes perspectivas de compreensão da realidade, e na percepção das implicações, que, expressas na comunicação entre os sujeitos, revelam posições de dominação culturais, econômicas, sociais e políticas. Tal diálogo com a realidade converge para uma das principais vantagens de desenvolver-se o ensino vinculado à pesquisa, no entender de Pan, Cotton e Murray 
(2014): respeitar o estudante como co-construtor não somente do conhecimento, mas da sua própria realidade social. A natureza metodológica do Projeto, voltada para a problematização e a intervenção em uma situação educacional presente na realidade, favoreceu o desenvolvimento dessa competência. Em $72 \%$ dos trabalhos, há relatos dos discentes quanto ao "espanto" frente à diversidade de posições assumidas pelos sujeitos envolvidos num mesmo contexto educacional, bem como à dificuldade em lidar com tal diversidade. Nas palavras de três dos grupos de alunos:

Ficou claro para o grupo, devido à imaturidade de início quanto ao conteúdo, que faltou atenção para problemáticas de relacionamento dentro do local - como o envolvimento dos responsáveis nas atividades propostas - pois os planejamentos e replanejamentos tiveram como finalidade a mudança de foco das atividades para atender as necessidades das crianças de quatro a seis anos do local, mas não da realidade vivida entre todas as pessoas que frequentavam o mesmo. Isso mostrou-nos que nossa ação teve certa limitação, ou seja, não envolveu o motivo pelo qual a principal problemática do local existia, mas somente sanou parte desse problema durante o desenvolvimento do projeto. (Grupo 5, 2011).

É preciso dialogar e refletir para ampliar nossa visão de mundo, percepção e conhecimentos; compreender o pensamento do outro sem julgá-lo como errado; enxergar o outro, aceitar e respeitar as diferenças; duvidar de nós mesmos e de nosso suposto controle sobre a gente e sobre as coisas do mundo. (Grupo 2, 2013).

Ao longo de nossas atividades, percebemos que as crianças apresentavam um quadro de agressividade, tanto física quanto verbal, de inibição para se expressarem perante o grupo e de não aceitação e respeito às regras de convivência. Saber lidar com essas crianças, escutá-las e entendê-las não foi uma tarefa muito fácil. No percurso da execução do projeto nos deparamos com situações relacionais bem delicadas, mais do que poderíamos imaginar. Percebemos que é muito complexo, para os professores, lidar com questões familiares, como com os pais e mães... é bem delicado. (Grupo 4, 2011).

Em relação à percepção das implicações ideológicas, que estariam presentes nos discursos dos contextos educacionais pesquisados, doze dos trinta e cinco trabalhos realizados (34\%) indicam claramente uma reflexão dos discentes pautada na consciência crítica quanto aos fatores socioeconômicos, políticos e culturais, que, presentes nos discursos dos contextos investigados, estão nas raízes da exclusão educacional e social dos sujeitos. Os demais trabalhos tangenciam, em maior ou menor grau, esta reflexão, prevalecendo, contudo, a consciência ingênua. Por consciência ingênua entende-se, acompanhando o pensamento freireano, aquela ainda 
não articulada com a práxis, que se caracterizaria pela sua tendência ao simplismo, ao elogio do "sempre foi assim" e às formas gregárias de agir, que se contenta com a experiência, sem avançar para a reflexão, frágil na argumentação, utilizando-se de alegações passionais, retóricas ou que remetem a uma espécie de pensamento mágico; que, enfim, trata a realidade como fixada, dada, antes do que construída (FREIRE, 1979). O recorte abaixo aponta para um exemplo de formação da consciência crítica, favorecida pela investigação feita pelos discentes:

A Educação Ambiental (EA), quando praticada de forma reflexiva e crítica, independente de ser formal, não formal ou informal, deve potencializar o poder da população, para que a mesma lute pelos seus direitos, participe das tomadas de decisões e seja árbitra dos princípios que privilegiam o lucro e o progresso econômico em detrimento do meio ambiente. Vale ressaltar que de nada adiantam políticas públicas e grandes projetos sociais e educativos, propostos de maneira geral, sem uma ação educacional efetiva. A concepção de educação caracterizada como bancária (Freire, 1975) aborda a problemática ambiental de modo artificial, fragmentada e sem o necessário debate crítico. (Grupo 5, 2013).

Os relatos discentes considerados como tendendo a uma consciência ingênua apresentaram principalmente a fragilidade argumentativa e a compreensão da ação educativa como intrínseca e fundamentalmente boa, no sentido de beneficiar igualmente a todos os sujeitos, mesmo quando os contextos investigados se mostraram resultantes de processos de dominação e de exclusão social, com as práticas pedagógicas colaborando para a manutenção desse quadro. Isso é o que pode ser exemplificado pelas investigações que tiveram por objeto a Educação de Jovens e Adultos (EJA) no ambiente escolar formal: o foco direcionou-se para a melhoria de técnicas instrucionais que pudessem favorecer o aprendizado, pouco havendo considerações, mesmo com o convite e o incentivo à reflexão, proposta pelos professores orientadores, sobre as condições sócio-históricas que promoveram a exclusão dos sujeitos do processo de escolarização. Pondera-se aqui que esse apego ao caráter instrucional da ação pedagógica se mostra influenciado pelo teor dos discursos educacionais difundidos, nas duas últimas décadas, que enaltecem o "aprender a aprender" e o "aprender fazendo" (SANTOS, 2013). Esses discursos, em seu cerne, privilegiam uma concepção educacional do aprender como resultado imediato do fazer, esvaziando-se a discussão e o pensamento didático-pedagógico quanto às razões do que- e para o que- aprender. Ou seja, dos princípios indagadores filosóficos que deveriam estar por fundamento de todo processo de ensino-aprendizagem. 
Em relação ao pensar democraticamente. Esta categoria compreendeu a consciência desenvolvida pelo discente na valorização da coletividade para a identificação e encaminhamento dos problemas enfrentados, o que passa pelo incentivo dos envolvidos na investigação a organizarem-se socialmente. Os dados indicam que dez dos trabalhos (cerca de 30\%) contemplaram plenamente essa categoria. Nos demais, há indicativos de incentivo à autonomia, à organização dos sujeitos para a participação na superação das problemáticas encontradas, mas de forma ainda incipiente. Em um relato, que teve como foco o Programa Escola da Família:

Espaço e verba mal utilizada, assim pode-se definir o Programa Escola da Família, nas escolas investigadas. É necessária uma gestão democrática, a população tem que participar, se manifestar, [...] deve-se buscar desenvolver projetos interessantes que envolvam os quatro eixos do programa: cultura, esporte, saúde e trabalho, e que realmente façam sentido para comunidades e não fiquem apenas restritos a atividades livres, comuns. Só assim o Programa Escola da Família vai conseguir uma real inclusão social, dando condições para a educação brasileira caminhar rumo a uma educação integral emancipatória. (Grupo 8, 2013).

E em outro, que teve como tema o desenvolvimento psicossocial de alunos com necessidades educacionais especiais

[...] a questão não é apenas incluir, mas, como incluir. É necessário que, na prática, seja adotada uma política educacional que promova mudanças curriculares, efetivando também a participação das famílias no processo de inclusão, instrumentalizando as escolas, capacitando e apoiando os profissionais que lidam com essas crianças, como alertam Marchesi e Martín (1995). E, principalmente, em nosso entender, desenvolvendo ações de pesquisa no cotidiano escolar, para que questões importantes à inclusão, como as habilidades sociais, sejam mais bem compreendidas e trabalhadas. (Grupo 6, 2013).

O pensar democraticamente fundamenta-se tanto numa atitude de equalização das relações de poder como na crença na capacidade das pessoas e comunidades para modificarem suas condições de vida. Isto exige aprender a confiar no outro, reconhecendo suas capacidades para viver em sociedade a partir da solidariedade, a igualdade na diferença e para criar canais de comunicação dialógicas, favorecendo a participação, a organização social e a tomada de decisões coletivas. Werneck (2000) afirma que para tanto é preciso passar de uma cultura da adesão- ou de incorporação da opressão-, historicamente predominante em nosso viver social, ainda como herança do nosso processo de colonização, para uma cultura de deliberação. Esta 
última depende da emersão de uma mentalidade proativa: "e essa mentalidade não é natural, tem que ser educada: é preciso aprender a passar de uma ordem recebida para uma ordem produzida" (WERNECK, 2000, p. 727). Consideramos que essa "cultura da adesão" traduziu-se em muitas das investigações feitas pelos discentes, tanto pela dificuldade que representa a ruptura com esse enquadramento cultural como pelas próprias características institucionais (casas abrigo, escolas, asilos, dentre outros) de muitos dos contextos investigados; consolidados na centralização do poder por grupos dominantes. Todavia o fato de um terço dos trabalhos realizados ter conseguido superar essas importantes barreiras, indica que a vinculação ensino e pesquisa pode contribuir relevantemente para a mudança apontada por Werneck, educando para uma cultura da deliberação. Isso se coaduna com os propósitos da Pedagogia Crítico-Democrática e com uma formação docente que se preocupe com ideais de equanimidade e justiça social.

\section{CONSIDERAÇÕES FINAIS}

Pretendeu-se, com este estudo, avaliar uma determinada proposta de vincular o ensino e a pesquisa na formação do pedagogo, o Projeto de Ação Educativa. Consideramos que a análise dos dados acima expostos indica que tal proposta, ao se fundamentar numa opção didática de conjugar o ensino e a pesquisa, acreditando na reciprocidade enriquecedora dessa relação para a formação pessoal e profissional do discente- mas também do docente- vem alcançando parcialmente o objetivo maior ao qual se propõe: formar o professor na perspectiva da educação como práxis. E, assim, preocupados e engajados com questões relacionadas à educação enquanto bem público. Os principais entraves encontrados na consecução desse objetivo mostraram-se relacionados ao: educar o discente para que este avance de um pensamento ingênuo para uma leitura crítico-reflexiva da realidade educacional e para uma vinculação mais estreita e consistente entre teoria e prática, de modo a reunir condições de direcionar problematizações e ações pedagógicas para além do aparente, rompendo com a "cultura da adesão".

Tais dificuldades, além das razões acima afirmadas, também se referem às arestas que permeiam a relação ensino e pesquisa, cujos fundamentos estão nas diferenças entre os paradigmas ontológicos, axiológicos e epistemológicos, que caracterizam a compreensão que a comunidade acadêmica tem do ensino e da pesquisa. A superação desses entraves e dificuldades somente transcorrerá num percurso contínuo e conjunto de formação pessoal e profissional, que deve envolver não somente 
alunos e professores, mas a instituição universitária como um todo. Mesmo porque outros fatores presentes no macronível do cotidiano do ensino superior, como o número de professores tempo integral, o espaço destinado na grade curricular para o ensino e a pesquisa, as formas de financiamento e o apoio institucional à pesquisa influenciam em como a relação ensino e pesquisa se efetivará no micronível da sala de aula, ou das práticas desenvolvidas com os alunos.

Nesse sentido, fatores do macronível que influenciaram positivamente nos resultados obtidos até o momento com o PAE são encontrados na atribuição da condução das atividades a professores doutores contratados em tempo integral; o assegurar de um número fixo de horas-aula semanais para as atividades de ensino e pesquisa, e a delimitação e sistematização curricular dessa iniciativa didática. E, também, a própria filosofia institucional, que tem, na educação dos jovens, em especial daqueles que convivem em contextos de vulnerabilidade socioeconômica, um dos seus pilares identitários.

A análise aqui realizada aponta, ainda, que a metodologia do PAE, pautada na associação ensino e pesquisa fundamentada no conceito de práxis no âmbito da Pedagogia Crítico-Democrática, pode ser aprimorada. Para tanto, consideramos que se faz necessário um esforço formativo para que os discentes articulem, com mais profundidade, as diversas perspectivas teóricas estudadas ao longo da graduação, contrapondo-as, analisando-as e entendendo-as em suas especificidades de compreensão da realidade. Também naquilo que se refere à reflexão-na-ação, envolvendo os alunos no engajamento ativo e persistente na consideração e reconsideração de suas experiências pessoais com as práticas educacionais investigadas, favorecendo a conscientização dos valores e crenças, pessoais e coletivos, que caracterizam essa relação. E, com base nessa conscientização, conjuntamente, perceber as múltiplas lentes ideológicas, que, presentes no entorno social, criam as concepções de gênero, etnia, raça, enfim, de ser humano, que permeiam o campo da educação. Isso torna esse campo conflituoso e prenhe de relações de dominação. E, acompanhando aquilo que tange ao imbricamento ensino e pesquisa, na construção de pontes que permitam aproximar a produção do conhecimento da aprendizagem do estudante, materializa a ideia de que todo saber construído está marcado, desde sua origem, pelas concepções ideológicas dos pesquisadores.

Colabora-se, assim também, para produzir junto com os estudantes um conhecimento não impessoal, entendido como aquele que se situa "fora" dos sujeitos, estéril para sensibilizar e promover o pensamento contra-hegemônico, caro à Pedagogia 
Crítico-Democrática. E, se as formas de conhecer produzem as formas de ser, como assegurado por esta teoria, estabelece-se uma coerência lógica entre o perfil profissional que se pretende com o PAE, isso é, aquele do professor pesquisador e crítico da sua prática, e a concepção de ensino e pesquisa aqui assumida.

O Projeto de Ação Educativa, em que pese aos seus limites, mostra, nos seus princípios articuladores, o potencial para formar o professor consciente do seu papel de questionador das assunções e práticas tidas como dadas, como "naturais", no cotidiano educacional, entendendo que também cabe a ele enfrentá-las. Mostra-se uma alternativa viável, no espectro da docência universitária, para uma educação mais autêntica e emancipatória, que não se configure como mero aprendizado técnico-instrumental.

\section{REFERÊNCIAS}

ARIMOTO, Akira. The teaching and research nexus in the third age. In: SHIN, Jung; ARIMOTO, Akira; CUMMINGS, William; TEICHLER, Ulrich (Ed.). Teaching and research in contemporary higher education: systems, activities and rewards. [S.I.]: Springer, 2014. p. 15-34.

BRASIL. Resolução CNE/CP 1/2006, de 16 de maio de 2006. Diário Oficial da União, Brasília, DF, Ministério da Educação, Seção 1, p. 11, 2006.

BREW, Angela. Research and teaching: beyond the divide. London: Palgrave Macmillan, 2006. BRYMAN, Andrew. Social research methods. Oxford, UK: Oxford University Press, 2008.

CHAUÍ, Marilena. Cultura e democracia. Crítica y Emancipación: Revista Latinoamericana de Ciencias Sociales, Buenos Aires, ano 1, n. 1, p. 53-76, 2008.

CUNHA, Maria Isabel. Docência na universidade, cultura e avaliação institucional: saberes silenciados em questão. Revista Brasileira de Educação, v.11, n. 32, p. 258-271, maio/ago. 2006.

FREIBERG, Regiane; BERBEL, Neusi. A importância da pesquisa como princípio educativo na atuação pedagógica de professores de educação infantil e ensino fundamental. Cadernos de Educação, Pelotas, RS, n. 37, p. 207-45, set./dez. 2010.

FREIRE, Paulo. Educação e mudança. 12. ed. Rio de Janeiro: Paz e Terra, 1979.

GIROUX, Henry. On critical pedagogy (critical pedagogy today). London/New York: Continuum International Publishing Group, 2011.

GRIFFITHS, Ron. Knowledge production and the research-teaching nexus: the case of the built environment disciplines. Studies in Higher Education, v. 29, n. 6, p. 709-26, 2007.

KINCHELOE, Joe. Critical pedagogy primer. 2. ed. New York: Peter Lang Publishing, 2008. 
LAMPERT, Ernâni. O ensino com pesquisa: realidade, desafios e perspectivas na universidade brasileira. Linhas Críticas, Brasília, v. 14, n. 26, p. 131-50, jan./jun. 2008.

MALCOLM, Mary. A critical evaluation of recent progress in understanding the role of the research-teaching link in higher education. High Education, v. 67, n. 3, p. 289-301, jul. 2013.

MANDÚ, Thamiris; AGUIAR, Maria Conceição. A formação inicial no curso de pedagogia: representações, caminhos e perspectivas dos estudantes. Educação Temática Digital, Campinas, SP, v. 15, n. 3, p. 560-77, set./dez. 2013. Disponível em: <https://periodicos.sbu. unicamp.br/ojs/index.php/etd/article/view/1273>. Acesso em: 15 jan. 2014.

MARTINS, Lígia; DUARTE, Newton (Org.). Formação de professores: limites contemporâneos e alternativas necessárias [online]. São Paulo: Editora UNESP/Cultura Acadêmica, 2010. Disponível em: <https://static.scielo.org/scielobooks/ysnm8/pdf/martins-9788579831034. pdf >. Acesso em: 24 fev. 2014.

NIXON, Jon. Interpretive pedagogies for higher education: Arendt, Berger, Said, Nussbaum. London: Continuum International Publishing Group, 2012.

PAN, Wei; COTTON, Debi; MURRAY, Paul. Linking research and teaching: contexto, conflict and complementarity. Innovations in Education and Teaching Internacional, v. 51, n. 1, p. 3-14, 2014.

SANTIAGO, Rui et al. Teaching and research: perspectives from Portugal. In: SHIN, Jung et al. (Ed.). Teaching and research in contemporary higher education. [S.I.]: Springer, 2014. p. 153-76.

SANTOS, Claudio. Crítica ao esvaziamento da educação escolar. Salvador: Eduneb, 2013.

SEVERINO, Antonio. Da docência no ensino superior: condições e exigências. Comunicações, Piracicaba, SP, ano 20, n. 1, p. 43-52, jan./jun. 2013.

SHIN, Jung; CUMMINGS, William. Teaching and research across higher education systems: typology and implications. In: SHIN, Jung et al. (Ed.). Teaching and research in contemporary higher education. [S.I.]: Springer, 2014. p. 381-94.

SKEAT, Walter. An etymological dictionary of the english language. New York: Dover Publication, 2005.

WERNECK, Nizia. Tecendo o amanhã - pela justiça na Educação. In: MARQUES, Antonio; BRANCHER, Leoberto (Coord.). Pela justiça na Educação. Brasília: Fundescola/MEC, 2000. p. 715-35. 


\section{Sobre os autores:}

Maria Luisa Bissoto: Doutora e Pós-Doutora em Educação, é docente do Programa de Pós-Graduação do UNISAL, campus Maria Auxiliadora, Americana, São Paulo, bem como dos cursos de graduação, na mesma instituição. Suas atividades de pesquisa estão ligadas à Educação Sociocomunitária. É a atual editora da Revista de Ciências da Educação, vinculada ao PPGE do UNISAL, Americana. Integra o grupo de pesquisa CAIPE- Conhecimento e Análise das Intervenções na Práxis Educativa Sociocomunitária. E-mail: malubissoto@yahoo.com

Antonio Carlos Miranda: Doutor em Educação, Docente do PPGE do UNISAL, campus Maria Auxiliadora, Americana, São Paulo. Integra o Grupo de Estudos HIPE e a Comissão Permanente de Avaliação. E-mail: antonio.miranda@am.unisal.br

Regiane Rossi Hilkner: Possui graduação em Pedagogia, Especialização e Mestrado em Psicologia da Educação pela Universidade Estadual de Campinas. É Doutora em Multimeios e Antropologia pela Universidade Estadual de Campinas. É professora do Centro Universitário Salesiano de São Paulo nos cursos de Pedagogia, Educação Inclusiva, Psicopedagogia e Ciência Contábeis. É também coordenadora dos Cursos de Pós Graduação Lato Sensu na área de Educação.Tem experiência na área de Educação, com ênfase em Psicologia e Antropologia Educacional, atuando principalmente nos seguintes temas: psicologia e metodologia educacional, desenvolvimento humano, fundamentos da educação, planejamento educacional metodologia da linguagem e pensar social. E-mail: regiane.hilkner@am.unisal.br

\section{Recebido em março de 2017}

Aprovado para publicação em setembro de 2017 